\title{
Research on the Issues Family Physicians Face Today: Controlled Substances, COVID-19, Hypertension, and "Slow Medicine," Among Many More Topics
}

\author{
Dean A. Seebusen, MD, MPH, Marjorie A. Bowman, MD, MPA, and \\ Christy J. W. Ledford, PhD
}

This issue of the JABFM features research on a broad array of clinical topics. The topics of 5 articles involve controlled substances, including a sobering article on the risks of amphetamines in older adults. An excellent quick reference guide for managing common COVID-19 symptoms is presented. Two other articles consider hypertension treatment in primary care, demonstrating that treating blood pressure is anything but straightforward. Several additional clinical topics include mononucleosis, influenza, and the impact of home life on childhood weight and eating habits. A study from Virginia underscores that primary care, as a system, is distressed. A review of the existing literature on "slow medicine" comes to important conclusions. Some health systems are partnering with local resources to practically address such social determinants as food insecurity. Not surprisingly, family physicians are filling gaps in emergency care around the country. ( $\mathrm{J}$ Am Board Fam Med 2021;34:1071-1073.)

Research on Clinical Topics

\section{Controlled Substances_Problems and Problem Prevention}

Four articles in this issue report on clinical issues related to controlled substances. Some clinicians prescribe amphetamines in older adults, expecting that a small dose is not related to adverse events. Dr. Latronica and coauthors ${ }^{1}$ analyzed evidence related to the safety of the quickly increasing use of amphetamines for attention deficit disorder in a database of more than 13,000 patients older than 65 years of age-about 5000 of whom were prescribed amphetamines. The results show dramatic increases in cardiovascular events.

Family physicians have heeded the dangers of opioid therapy for chronic noncancer pain and are altering their narcotic prescribing approach for these patients. This change is challenging for both clinicians and patients. Suen et $\mathrm{al}^{2}$ explored the patient's perspective on these shifting norms in opioid therapy for chronic noncancer pain. A report from Russell et $\mathrm{al}^{3}$ demonstrates that even with training, many challenges remain to significantly increasing the numbers of family physicians prescribing buprenorphine.

Conflict of interest: The authors are editors of the $7 A B F M$.
One tool that can address these challenges is the benchmark tracking assessment Sussman et $\mathrm{al}^{4}$ developed to guide clinicians through the process of implementing buprenorphine therapy. Family physicians need other tools to address the ongoing, and apparently growing, substance use epidemic. Would clinicians be open to using a clinical support tool to manage opioid use disorder, and what would it need to be like to assist primary care clinicians to manage opioid use disorder? Further, would clinicians use it? Solberg et al report on their findings. ${ }^{5}$

\section{COVID-19}

The fournal is pleased to publish a quick-reference guide for management of post-COVID symptoms for primary care clinicians created by a multidisciplinary group from the University of Michigan. ${ }^{6}$ Most practices went through dramatic increases in telemedicine during the early phases of the COVID-19 pandemic. A report of how telemedicine changed in the pandemic highlights some of the challenges and solutions found by 36 community health center centers across New York state, 1 of the hardest-hit regions. ${ }^{7}$

\section{Hypertension}

Hypertension guidelines have undergone considerable changes over the last several years. A thought- 
provoking report by Rogers et $\mathrm{al}^{8}$ explores potential unintended consequences of guidelines that result in clinicians prescribing multiple antihypertensive medications for patients. This report is a good reminder that all clinical decisions have consequences, not all which are immediately obvious. Hypertension control has deteriorated, and Solberg et $\mathrm{al}^{9}$ investigated what could be improved. By considering the disparate reasons noted by patients who were dissatisfied with their care, the authors identified 4 major types of issues, each requiring a different clinician approach. This suggests the need to both inquire, then listen carefully to patients to mutually find an acceptable path to improved adherence and blood pressure control.

\section{Other Clinical Topics}

Ebell et $\mathrm{a}^{10}$ evaluated a range of clinical prediction rules for diagnosing influenza. Importantly, their findings suggest that such a rule could play an important role diagnosing this common infection without bringing sick people in for an examination. Cai et $\mathrm{al}^{11}$ present a thorough systematic review and meta-analysis of the accuracy of laboratory findings, as well as signs and symptoms, of infectious mononucleosis.

A hint for family physicians wondering about the adherence rate for chronic medications by their patients: look at how well they follow prevention screening recommendations. ${ }^{12}$

Methotrexate can be a very useful drug. However, when a dosing error is made, it can have very serious consequences. The type of most common errors suggest that patients need even-greaterthan-usual assistance to avoid problems. ${ }^{13}$

Life with children can be chaotic at times, and some homes operate with a higher baseline level of chaos and stress than others. Does CHAOS correlate with health outcomes? A study of home environment profiles and childhood body mass index, among other outcomes, looks at this issue. ${ }^{14}$ The next challenge will be to determine how clinicians should counsel patients based on these study findings.

\section{Health Systems Research}

Slow medicine is not the norm in the US health care system. Yet many (perhaps most) family physicians have a gut feeling that it is often a better approach. Marx and Kahn ${ }^{15}$ report on a broad- ranging review of the topic and identified some tantalizing hints about that gut feeling. The authors make the case that slow medicine needs to be taken more seriously by researchers and policy makers.

Clinicians are increasingly attempting to address the social determinants of health. To address food insecurity, collaborations between community food sources and health systems are likely to be more common in the future. An analysis of 1 such collaboration involving the Mid-Ohio Farmacy found a mix of successes and barriers to the program. ${ }^{16}$

How many specialist referrals do family physicians, on average, make for patients? A report from a single academic institution shows surprisingly wide differences. The authors were able to identify some associations with variable referral rates but also evidence that there is room for improvement in family medicine training. ${ }^{17}$

Brooks et $\mathrm{al}^{18}$ offer a snapshot of the primary health care system in the Commonwealth of Virginia. They describe significant challenges existing for a system that functions as a safety net for many of the commonwealth's most vulnerable patients. The sobering aspect of the report is that the data were collected before 2 major stressors, Medicaid expansion and COVID-19, occurred. Clifton et $\mathrm{al}^{19}$ investigate burnout in team members across 41 family physician practices, and not just among the health care professionals. Notably, the family medicine residents were the most distressed.

Bennett et $\mathrm{al}^{20}$ provide yet more evidence of family medicine's large and diverse impact on the American health care system. This team studied the AMA's Physician Masterfile to create an estimate of the amount of emergency medicine conducted in the nation by family physicians. The results, especially in some underserved areas, are impressive.

To see this article online, please go to: http://jabfm.org/content/ 34/6/1071.full.

\section{References}

1. Latronica JR, Clegg TJ, Tuan WJ, Bone C. Are amphetamines associated with adverse cardiovascular events among elderly individuals? J Am Board Fam Med 2021;34:1074-1081.

2. Suen LW, McMahan VM, Rowe C, et al. Factors associated with pain treatment satisfaction among patients with chronic non-cancer pain and substance use. J Am Board Fam Med 2021;34:1082-1095.

3. Russell HA, Loomis E, Sanders M, Mullaney T, Meyer JKV, Fiscella K. Increasing access to 
medications for opioid use disorder in primary care: removing the training requirement may not be enough. J Am Board Fam Med 202 1;34:1212-1215.

4. Sussman AL, Crawford JN, Brakey HR, et al. Use of a benchmark tracking assessment to support expansion of buprenorphine for treatment of opioid use disorder in primary care. J Am Board Fam Med 2021;34:1216-1220.

5. Solberg LI, Hooker SA, Rossom RC, Bergdall A, Crabtree BF. Clinician perceptions about a decision support system to identify and manage opioid use disorder. J Am Board Fam Med 202 1;34:1096-1102.

6. Vance H, Maslach A, Stoneman E, et al. Addressing post-COVID symptoms: a guide for primary care physicians. J Am Board Fam Med 2021;34:1229-1242.

7. Chang JE, Lindenfeld Z, Albert SL, et al. Telephone vs. video visits during COVID-19: safety-net provider perspectives. J Am Board Fam Med 2021;34:1103-1114.

8. Rogers EA, Abi H, Linzer M, Eton DT. Treatment burden in people with hypertension is correlated with patient experience with self-management. J Am Board Fam Med 2021;34:1243-1245.

9. Solberg LI, Crain AL, Green BB, et al. Experiences and perceptions of patients with uncontrolled hypertension who are dissatisfied with their hypertension care. J Am Board Fam Med 2021;34:11151122 .

10. Ebell MH, Rahmatullah I, Cai X, et al. A systematic review of clinical prediction rules for the diagnosis of influenza. J Am Board Fam Med 2021;34:11231140 .

11. Cai X, Ebell MH, Haines L. Accuracy of signs, symptoms, and hematologic parameters for the diagnosis of infectious mononucleosis: a systematic review and meta-analysis. J Am Board Fam Med 2021;34:1141-1156.

12. Shani M, Schonmann Y, Comaneshter D, Lustman A. The relationship between patient medication adherence and following preventive medicine recommendation. J Am Board Fam Med 2021;34:11571162 .

13. Thompson JA, Love JS, Hendrickson RG. Methotrexate toxicity from unintentional dosing errors: calls to a poison center and death descriptions. J Am Board Fam Med 202 1;34:1246-1248.

14. Buchanan GJR, Tate AD, Loth KA, Trofholz AC, Berge JM. CHAOS in the home environment and child weight-related outcomes. J Am Board Fam Med 2021;34:1163-1173.

15. Marx R, Kahn JG. A narrative review of slow medicine outcomes. J Am Board Fam Med 2021;34:1249-1264.

16. Walker DM, DePuccio MJ, Hefner JL, et al. Utilization patterns of a food referral program: findings from the Mid-Ohio Farmacy. J Am Board Fam Med 2021;34:1174-1182.

17. El Ayadi H, Desai A, Jones RE, et al. Referral rates vary widely between family medicine practices. J Am Board Fam Med 2021;34:1183-1188.

18. Brooks EM, Huffstetler A, Britz J, et al. The distressed state of primary care in Virginia preMedicaid expansion and pre-pandemic. J Am Board Fam Med 2021;34:1189-1202.

19. Clifton J, Bonnell L, Hitt J, et al. Differences in occupational burnout among primary care professionals. J Am Board Fam Med 2021;34:1203-1211.

20. Bennett CL, Gerard WA, Cullen JS, et al. National study on the contribution of family physicians to the US emergency physician workforce in 2020. J Am Board Fam Med 2021;34:1221-1228. 